\title{
Tangible data souvenirs as a bridge between a physical museum visit and online digital experience
}

\author{
Daniela Petrelli $^{1} \cdot$ Mark T. Marshall $^{1} \cdot$ Sinéad O'Brien $^{1} \cdot$ Patrick McEntaggart $^{1}$ \\ Ian Gwilt ${ }^{1}$
}

Received: 8 July 2016/ Accepted: 30 October 2016/Published online: 26 November 2016

(c) The Author(s) 2016. This article is published with open access at Springerlink.com

\begin{abstract}
This paper presents the design, implementation, use and evaluation of a tangible data souvenir for an interactive museum exhibition. We define a data souvenir as the materialisation of the personal visiting experience: a data souvenir is dynamically created on the basis of data recorded throughout the visit and therefore captures and represents the experience as lived. The souvenir provides visitors with a memento of their visit and acts as a gateway to further online content. A step further is to enable visitors to contribute, in other words the data souvenir can become a means to collect visitor-generated content. We discuss the rationale behind the use of a data souvenir, the design process and resulting artefacts, and the implementation of both the data souvenir and online content system. Finally, we examine the installation of the data souvenirs as part of a long-lasting exhibition: the use of this souvenir by visitors has been logged over 7 months and issues around the gathering of user-generated content in such a way are discussed.
\end{abstract}

Daniela Petrelli

d.petrelli@shu.ac.uk

Mark T. Marshall

m.marshall@shu.ac.uk

Sinéad O’Brien

contact@sineadobrien.net

Patrick McEntaggart

p.mcentaggart@shu.ac.uk

Ian Gwilt

i.gwilt@shu.ac.uk

1 Art and Design Research Centre, Sheffield Hallam University, Cantor Building - 153 Arundel Street, Sheffield S1 2NU, UK
Keywords Tangible interaction - Data souvenir · Museums · User-generated content

\section{Introduction}

Museums have begun to focus on the visitor experience as a process that is not limited to the time spent in the museum itself. Indeed, as Falk and Dierking state: "The museum experience begins long before the visitor arrives and continues long after the visit" [10, page 284]. While the pre-visit is focussed on providing information, e.g. about both the collection and practical issues around the visit, the post-visit aims at establishing a long-lasting relationship that can foster additional visits and word-ofmouth promotion [6]. To keep visitors engaged, museums have started to experiment with new media channels to encourage visitor participation, such as the use of social media as a means for visitors' active contribution $[7,11,16,29]$. The intent of sustaining a long-term connection with visitors via digital media is, however, disconnected from the physical experience of visiting an exhibition or an historical place. Examples of online experiences include creating a personal collection of artworks from the museum digital collection ("Make your own imagined museum" by the Tate ${ }^{1}$ ), engaging in a creative activity and sharing the result ("Design your wig" by the $\mathrm{V} \& \mathrm{~A}^{2}$ ) or contributing personal digital items to an online exhibition ("VanGoYourself", which reuses content from the Europeana repository ${ }^{3}$ ). As a matter of fact, the

\footnotetext{
$\overline{1}$ http://www.tate.org.uk/art/albums/list?category=imagined-museum (accessed 21.7.2016).

${ }^{2}$ http://www.vam.ac.uk/designawig/ (accessed 21.7.2016).

${ }^{3}$ http://vangoyourself.com/ (accessed 21.7.2016).
} 
material collection and the online presence are often managed by different departments with the result of offering two distinct and separate experiences to visitors. By combining principles from ubiquitous computing and tangible interaction, it is possible to close the gap currently existing between the exhibition floor and the online services and design visitor experiences that take both aspects into account [26]. The digital and the material can become components for the design of a holistic visitor experience that crosses the digital-material boundary. The challenge is in weaving the digital and the material to create seamless immersive and novel visitors' experiences.

In this paper, we explore the value of personalised tangible data souvenirs as a bridge between the physical, personal experience of the visit and the digital online experience of staying engaged with the museum. We define personalised tangible data souvenirs in the context of a museum experience as specific material representations of individual visiting paths: the visit is dynamically recorded by logging information such as where the visitor is at particular points in time and what exhibit he/she is attending to. These data are then processed to create a tangible embodiment of this personal experience. The data are the digital shadow of the physical experience, and the tangible data souvenir can be used to access a personalised online space that displays the visit against the whole exhibition and enables visitor contribution. By creating a personalised data souvenir, it becomes possible for museums to present visitors with a physical memento of their visit while offering them the possibility to further interact with the museum and its content, revisit their experience or contribute their stories. Such interaction can also provide a useful opportunity for the museum to gather visitor-generated content and thus continuously enrich the physical exhibition through novel digital material.

This paper is organised as follows: the next section discusses research relevant to the topic of this paper. This is followed by the description of the Atlantic Wall exhibition and the visitor experience. We then describe the system architecture and how it connects the interaction onsite and online. Next is the design process of the data souvenir and the challenges of proposing a solution viable for museums that have very low maintenance and high impact, such as the printing of a personalised postcard. Following this, we discuss the personalised website (created by processing the data collected during the visit) that enables visitor contributions. Finally, we present the results of 7 months of the data souvenir being used in an exhibition. We conclude the paper with reflections and guidelines.

\section{Related work}

This research lies at the intersection between museum studies, new forms of digital fabrication, personalisation and ubiquitous computing. Although much research has been carried out in each area in recent years, e.g. the many forms of digital fabrication, this work has been going on independently and their combination in a novel and unique museum experience has not yet been pursued. In an attempt to bring together the different strands, here we discuss how the different components can contribute to the creation of personal tangible data souvenirs as part of the museum visit.

Museums are nowadays considered an example of leisure activity pursued not necessarily for educational goals: they offer a peaceful environment for those in need of recharging and often are a must-see destination in the tourist's agenda [9]. Visitors have different needs and even the same person can look at the same exhibit many times, each time in a different way and with different expectations [9]. A number of scholars in museum studies (e.g. $[8,24,32,35])$ see value in revisiting the informationcentric approach of cultural heritage in favour of one that enables visitors to be in direct contact with objects and places. Making visitors feel emotions, challenging their beliefs with difficult questions and enabling personal meaning making are new goals for curators. Instead of offering visitors a definitive pre-packed curator-led interpretation to absorb and learn, more forward-looking museums offer multiple, possibly conflicting, voices and leave the act of interpretation to the visitors, while acknowledging that their different personal backgrounds, expectations and needs change the way they engage with heritage holdings [9]. The premise that information is not the only or most important factor impacts on the way in which designers should think about digital interaction with heritage. Factors such as physical engagement and supporting the social setting are principles that interaction designers should consider [27].

Issues with technology in museums were noted as early as 1992: visitors enjoyed interactive multimedia, but they did not have the time or patience for the kind and amount of details provided [28]. The focus should be on how the information is received rather than how it is delivered [28]. Twenty years later, we see the story repeated: a study of tabletop interaction in a museum showed $50 \%$ of visitors did not touch the table, only $17 \%$ had more than one-touch interaction and only a few conversations around the table focussed on the topic of the exhibition [15]. The situation is not that different with mobile guides (PDAs initially, smartphones now): mobile devices extend the time visitors devote to interaction with technology, but time might be spent in understanding how the device itself works and not in visiting and interacting with the heritage [14]. Mobile guides focus the visitor's attention on the screen in their hand to the point, in some cases, of ignoring the exhibits [34] or choosing what to look at on the basis of what is on the screen [31] instead of what is of personal 
interest. Enabling and supporting visitors' choice is key for actual engagement and enjoyment. Advancements in ubiquitous computing have the potential to mitigate some of the issues with mobile technology, for example by reducing the number of items accessible through the phone at each point in time during the visit to those exhibits that are in the immediate vicinity [4, 5]. However, radically different solutions are possible. As in the case of the Atlantic Wall exhibition discussed in this paper, ubiquitous computing can be implemented in a completely transparent way: by concealing technology within the environment, the experience is not affected by possible issues with the device.

An exhibition or a museum can make a lasting impression on the visitor and buying souvenirs is a common way to mark and remember a special experience. A large body of evidence supports this, particularly in relation to tourism $[2,12,13,21]$. While the most common experience is to buy a souvenir after the visit, there is evidence to suggest that the souvenir should instead be an integral part of the visit itself, it should be constructed during the visit in such a way that it becomes the embodiment of the personal experience [19]. Digital manufacturing has opened new opportunities for creating artefacts as part of a visit. For instance, [23] experimented with the digital making of self-designed/self-assembled souvenirs in the context of an extended experience of a single art installation. Their findings show different attitudes to the making and the souvenir depending on how intensely the visitor experiences the exhibit: the making could be the focus of the experience, a way of reflecting and making sense of the artwork, or a way of capturing the experience into a memento [23]. This interesting experiment, however, cannot be applied to a real museum setting, as it is impossible to have personnel available for a one-to-one making session. In addition, the reflective activity was designed around a single art piece everyone experienced; in a museum each visitor follows a personal path and experiences different things with the result that no two visits are the same, even for people visiting together.

To be able to automatically create a personal souvenir of a museum visit, it is necessary to collect data about the visit itself, via sensor logs, and to give meaningful form to that personal data set. A unique example is a summary of the visit just concluded, which is automatically generated on the basis of the visit logs [30]. A personalised summary is a reminder of the actual visit, but does not have the physical qualities of a souvenir, that of being a beautiful, physical object kept as a memento of an experience.

Experiments with the materialisation of personal data into beautiful objects have so far looked into data from sport [17] or craft [22] activities or the monitoring of email use [1]. These materialisations are an abstraction of the activity, and they need to be explained to be properly interpreted; they are a secret code into personal performance over time. For example in [17], the record of a single physical activity is engraved with a specific line pattern that captures the frequency of a specific motion; multiple activities over time create different lines and contribute to the unique aesthetic of the personal bracelet.

The use of digital technology to fabricate personalised objects does not change the passive nature of objects created exclusively to be looked at and function as reflective [23] or motivational [17] pieces. Digital technology can take the fabrication much further and make the physical object an entry point for a further personalised digital service that makes use of the onsite visit log to extend the experience online in the form of a post-visit environment offered by the museum to visitors. Museums have long acknowledged the importance of a long-term connection and communication with visitors, but the focus so far has been on specific activities for school visits and informal learning $[20,33]$. We see much potential in extending this approach to all visitors and enabling museums to start a long-term relationship with visitors, many of whom are returning visitors $[9,25]$.

To summarise, from a visitor's point of view a souvenir of a museum visit should hold a clear connection to the exhibition or collection and should represent somehow the personal journey. From a museum point of view, the creation of a souvenir should be low cost and maintenancefree. So far research has not tackled any of these issues. Furthermore, a souvenir is seen as a passive object, a reminder of the past. A personalised souvenir can extend the interaction into the future by offering new ways for museums to connect with visitors, e.g. by matching the visit with additional curated online content or by enabling visitors to contribute to a growing collection of visitorgenerated content. In other words, the personalised tangible souvenir becomes the means for a long-term visitor-museum interaction that connects the physical and the digital.

\section{The Hague and the Atlantic Wall}

The tangible personalised data souvenir in this paper was part of the design of the exhibition "The Hague and the Atlantic Wall: War in the City of Peace" which ran from April to October 2015 at MUSEON in the city of The Hague, in The Netherlands. The exhibition was conceived as a stand-alone setting to which the technology was added as an enrichment. In other words, it was the intention of the exhibition curators that visitors would be able to enjoy and appreciate the exhibition without using any technology at all. The topic was expected to appeal a large range of visitors; in particular, the museum expected a higher 
number of elderly than usual and it was therefore key to care for all attitudes and abilities.

The Atlantic Wall was a set of defensive lines and placements that were built by the German forces during WWII along the coast of the Atlantic Ocean and North Sea, from the French/Spanish border to Norway. The wall consisted of a $5000 \mathrm{~km}$ long chain of bunkers, anti-tank walls, cliffs and other barriers and was aimed at preventing an Allied attack on the Reich's Western frontiers. The presence of these fortifications affected several countries and cities and their residents.

The exhibition focused specifically on the Atlantic Wall in The Hague. In this coastal city, the construction of the Atlantic Wall was rather different from the rest of the defensive line, both because The Hague was the seat of the administration of the occupied Netherlands and because of the presence of a fishing port, meaning it needed additional protection. As the Allied forces could break through the coastal defence lines and reach The Hague from inland, a second defence line was created through the city itself. Thousands of buildings were demolished to give way to an anti-tank ditch and an anti-tank wall. Tens of thousands of people had to leave their homes and be relocated to other parts of the Netherlands. Some parts of the city were no longer accessible to the inhabitants without special permits or were completely closed off to civilians.

The exhibition dealt with the impact of the construction of the wall on the city and its inhabitants. Subjects such as evacuation and daily life in an occupied city that had become a military fortress were important in the exhibition's storyline. The story was told by means of museum objects, documents, maps, models, photographs and videos all displayed in an evocative environment (Fig. 1). The exhibition space was arranged to correspond to a physical map of The Hague, and showcases were marked as locations within the city. Ten interactive display cases were spread across a single open-plan space, along with an

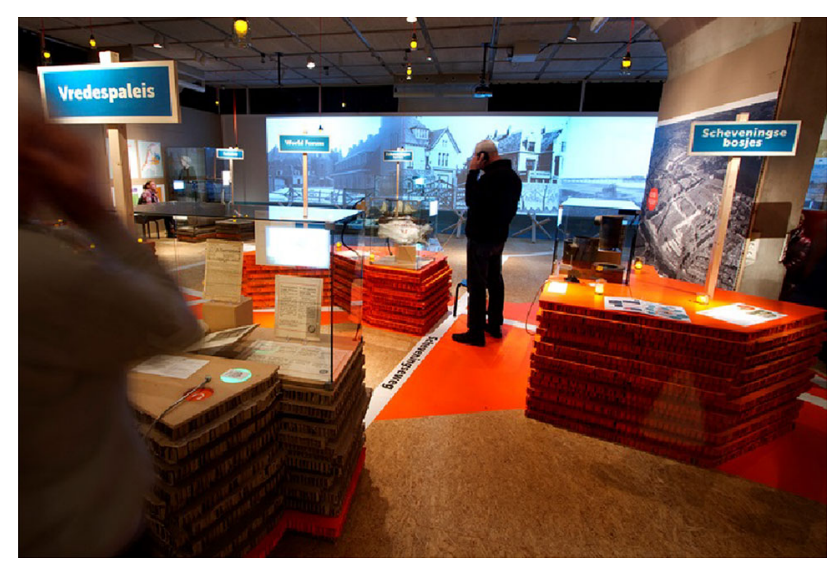

Fig. 1 Visitors interacting with the Atlantic Wall exhibition introductory video projection. Here below we summarise the interactive experience, interested readers can refer to a more extended description and discussion in [18]. While the interaction at the cases was essential in order to collect the logs, in this paper we focus on bridging the physical and the digital and therefore the conclusion of the onsite experience and the continuation online.

To enrich the visit experience, a set of personal stories were prepared by the curators and recorded using actors in order to provide affective content to complement the factual, more traditional textual descriptions. The intention was to offer a richer variety of personal accounts than generally available, going beyond the presentation of facts and more into the personal and affective recounting of dramatic events. Playback of the personal stories was triggered by smart replicas; reproductions of original exhibition objects augmented with digital technology (in this case, NFC tags). Each replica represented a single perspective on the story of the Atlantic Wall: that of a Civilian displaced from their home, a Civil Servant (Official) unwilling to be the instrument of the implementation of the occupiers' plan, or an occupying German soldier who felt himself a protector of the Dutch population against potential invaders.

The exhibition had textual information in two languages, Dutch and English, and therefore, 2 sets of 3 smart replicas were created. Each replica represents one of 3 perspectives in one of 2 languages. The replicas and their collection point within the exhibition are shown in Fig. 2. When entering the exhibition, the visitor chooses one of these replicas and carries it around the exhibition to interact with the display cases. If, for example, the visitor chooses the dictionary for their visit, they will choosing the German soldier perspective in English (top left in Fig. 2).

Table 1 shows the mapping of objects to perspectives and languages.

Each replica contained an NFC tag that allows the physical item and its user to interact with the display cases. Next to each display case was a pulsing orange circle, under which was placed an NFC reader. When a replica was placed on the circle, the colour changes to a solid green, indicating that the case has been activated (Fig. 3) and audio played through the earpiece, while images were projected on the case front glass. The use of the replica was monitored and information logged: when the replica was placed on an NFC reader, the showcase number, the perspective represented by the replica and a timestamp were logged; similar information was recorded when the replica was removed thus enabling the system to fully track the visit.

The visitor was free to move around the exhibition visiting cases in any order they wished. When they decided to end their visit, they would go to the souvenir printing 


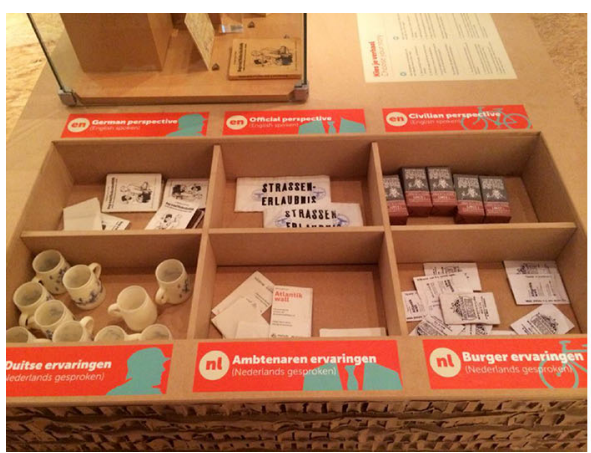

Fig. 2 The smart replicas at the pick-up point. The top row is for the English language, from left to right: a German-Dutch pocket dictionary for the German perspective; an armband that granted permission to cross the lines for the Official (Civil Servant) perspective; a box of sugar surrogate for the Dutch civilian

Table 1 The list of replica objects and their corresponding perspective and language

\begin{tabular}{lll}
\hline Replica & Language & Perspective \\
\hline Tea bag & Dutch & Civilian \\
Sugar & English & Civilian \\
Travel Pass & Dutch & Civil Servant \\
Armband & English & Civil Servant \\
Drinking mug & Dutch & German soldier \\
Dictionary & English & German soldier \\
\hline
\end{tabular}

station. Here, the replica ended the visit session, triggering the system to process the log data and generate a data souvenir: a personalised card on which the visit is represented. Beside the souvenir station was an interactive tabletop displaying the online map to invite visitors to explore the stories contributed by other visitors. In this way, the online visitor contributions were part of the exhibition itself. It was also expected that, by seeing other

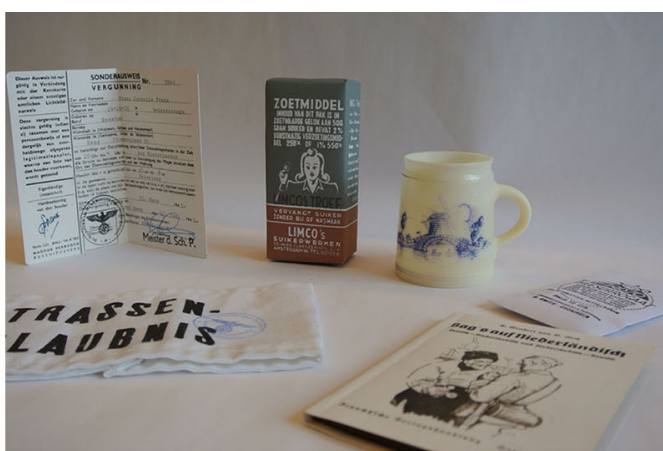

perspective; The bottom row is for the Dutch language, from left to right: a beer mug given as Christmas present to the German soldiers for the German perspective; a printed pass that allowed crossing the lines for the Official (Civil Servant) perspective; and a surrogate tea bag for the Dutch civilian perspective

visitors' content, visitors were encouraged to consider contributing. The possibility of allowing visitors to contribute while still at the museum was considered at the design phase. Given the sensitive topic, the curators decided to moderate the content before its publication on the map; therefore, a dynamic upload of personal stories was not appropriate and the tabletop enables viewing but not uploading. The personalised souvenir, a postcard, printed at the end of the visit, contained all the necessary information to go online, revisit the experience, get further material available in the exhibition and contribute content in the form of personal and family memories, as described below.

As with the other cases, at the souvenir station the visitor placed their replica on the pulsing orange circle (Fig. 4, top left). A video then played containing instructions and the postcard-like data souvenir was printed (Fig. 4). The front of the postcard was personalised with the language and perspective of the visit, along with the three cases at which the visitor spent the most time. This information was extracted from the log recorded during the visit. The three most seen cases were printed as stamps as a reminder
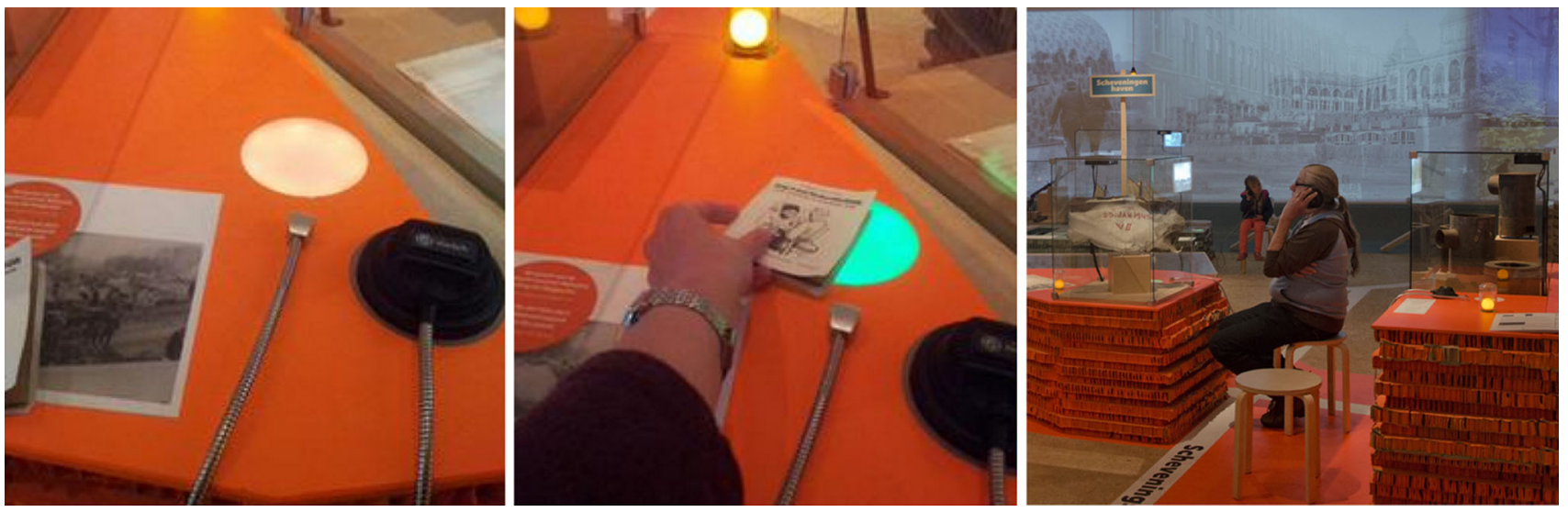

Fig. 3 The use of a replica (the German-Dutch dictionary for the Soldier perspective) at a showcase point 


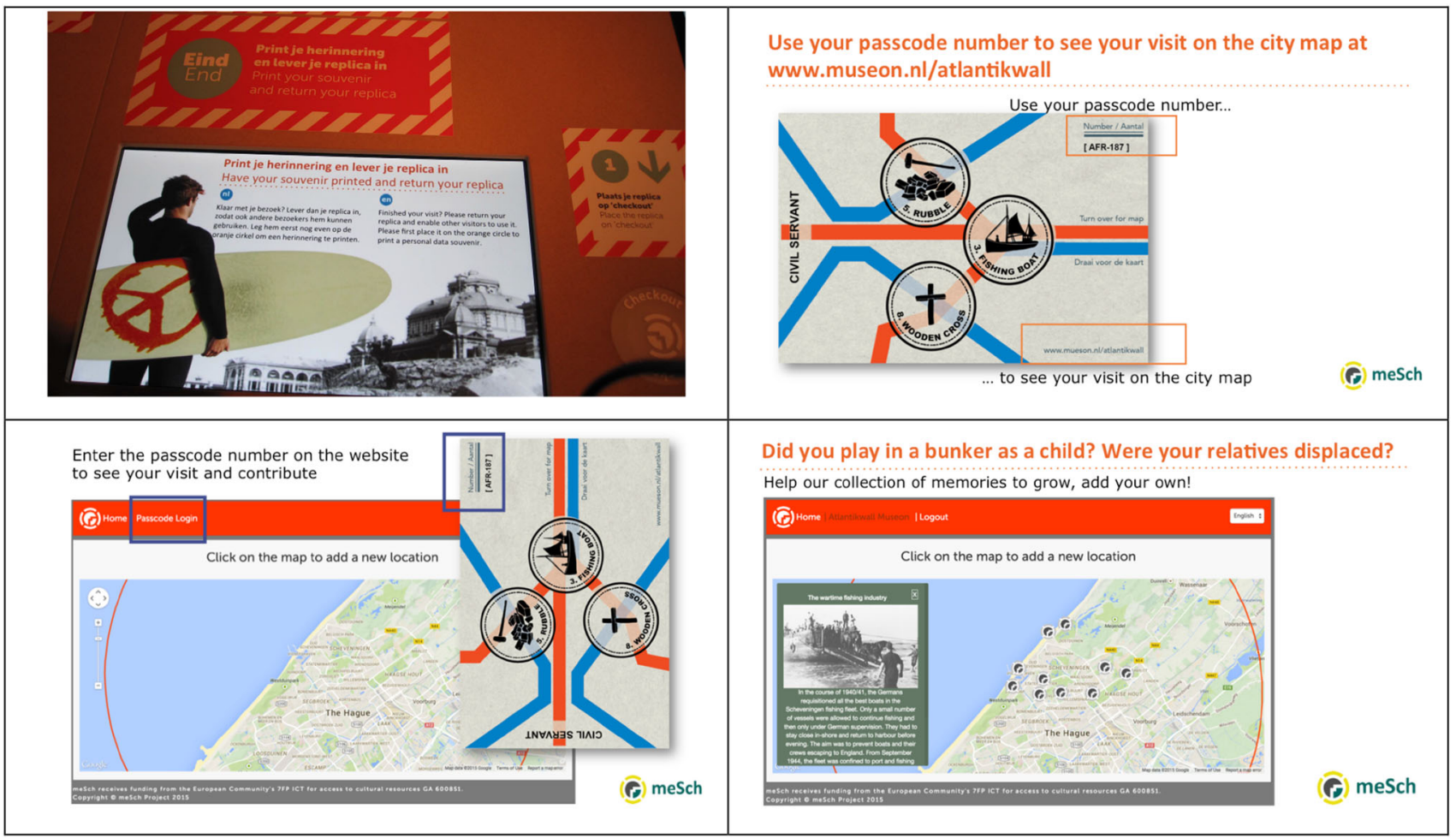

Fig. 4 Key frames from the instructional video on how to use the postcard as displayed at the souvenir station

passes that needs to be stamped to be allowed through (Fig. 8). The card also included a unique passcode and prompted the user to visit the post-visit website. The back of the postcard shows a map of the city together with a reference to the corresponding locations in the city (Fig. 8). In this way, a relationship between the exhibition and the city outside the museum's walls is established. This connection between the experience of The Hague during the war and The Hague today was reinforced by a large interactive map positioned next to the personalised card printing station. The interactive tabletop displayed usergenerated content relevant to the Atlantic Wall and located on a map of the city today. The curators were willing to collect personal memories and stories, photographs from personal archives or any form of visitors' contribution, e.g. selfies on relevant spots. A few contributions from friends of the museum were used to provide some initial content for the map. The next section describes the design process of the card as a souvenir of the personal visit and its use as an element of the Atlantic Wall exhibition.

The postcard has a unique code printed on the top right corner (Fig. 9). Using this passcode and the website address provided on the data souvenir, the visitor could elect to go online to continue the interaction with the exhibition and to add their own content to this map. The online post-visit experience was designed around an interactive map of the city of The Hague; places in the exhibition were marked on the map, and colour was used to show whether the place had been visited in the exhibition or whether instead it was new content to the visitor. Standard map place markers were used to show visitors' contributions; clicking on the place marker would display the content.

\section{System architecture}

While the visitor may not be aware digital technology enables their experience as it is completely concealed in the replicas and the cases, a bespoke software system paired with ubiquitous computing (NFC tags in the replicas and NFC reader in the interactive rings) is what makes the Atlantic Wall exhibition interactive. Figure 5 shows the different layers and components: the Application Layer controls the interaction with the visitors both onsite and online; the Service Layer provides the backend functionalities; and the Data Layer manages the content (i.e. the videos) and the logs (i.e. the recordings of how each replica has been used).

The Application Layer contains the modules that directly interact with the visitors both onsite and online. The Onsite Network subsystem manages all the interactive cases: when a replica is placed on a Case, it requests to the Event Processor the corresponding video to the Content 
Fig. 5 The system architecture over three layers. The

Application Layer manages the visitor interaction online and onsite; the Service Layer enables the system functionalities; and the Data Layer manages both the videos displayed as each case (Content) as well as the log collected for each smart replica used in the exhibition

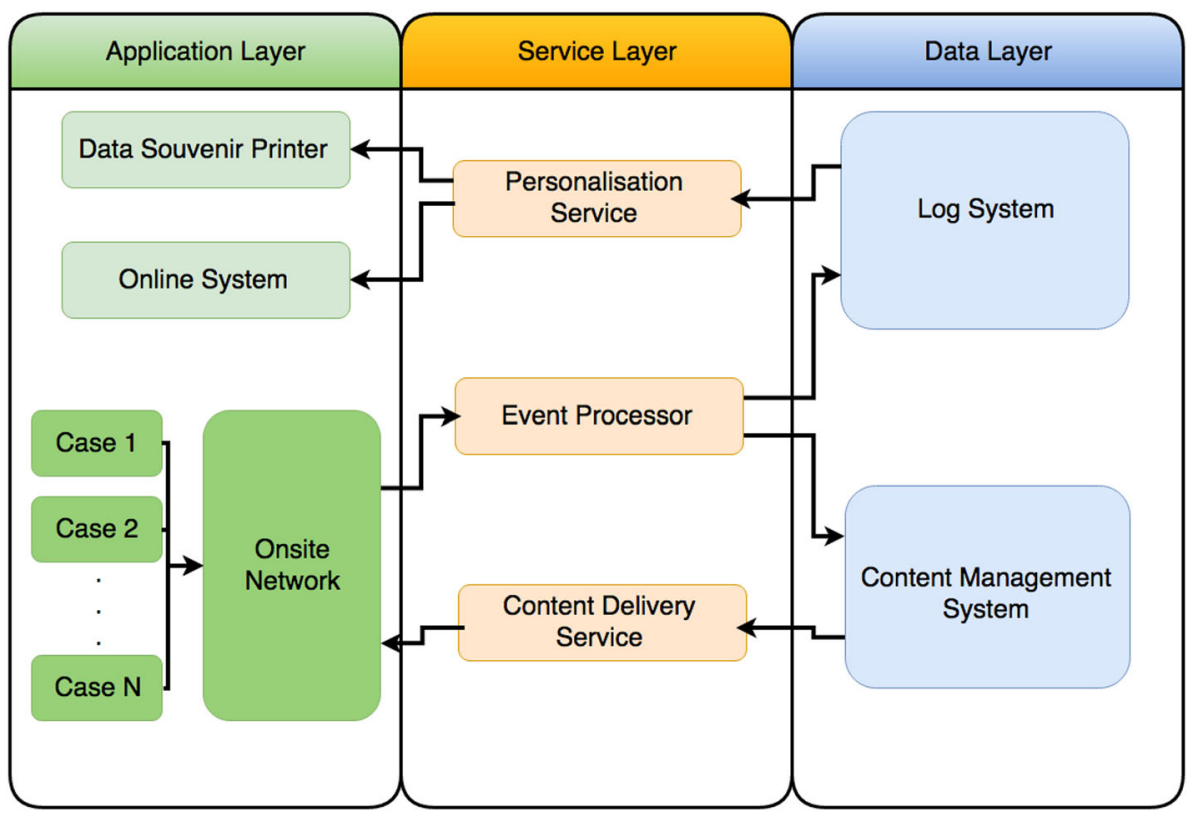

Management System (in the Data Layer); the video is then passed to the Content Delivery Service (in the Service Layer) to the Onsite Network to be displayed on a Case. When the replica is removed from the ring, the Onsite Network requests the Event Processor (in the Service Layer) to record for how long the replica was used at that specific Case; this information is stored by the Log System in the Data Layer and later used for printing the souvenir and in the online visualisation. While the visitor progresses in their visit, the Onsite Network is repeatedly called and the same process of content request, display, and log storage is repeated. When the visitor concludes the visit and approaches the printing station, the Event Processor activates (via the Log System and the Personalisation Service) the Data Souvenir Printer to generate the postcard. Finally, when the visitor uses the code on the postcard to enter the website via the Online System, the Personalisation Service uses the $\log$ in the Log System to visualise the content as "seen" or "new" depending on the record of the visit associated to that specific code. Figure 6 shows how the components in the system architecture are activated at different phases of the visit; it follows a hypothetical visitor within the exhibition and later online.

\section{Tangible data souvenir}

The design brief was to create a souvenir that fit with the theme of the exhibition, while being easily produced in the thousands with minimal maintenance and also offering layers of information to the visitor. This included a representation of some aspects of their visit, the connection between the displays within the exhibition and the city of The Hague and access to an online post-visit experience where the visitors could find curated content as well as visitor-generated content, such as personal and family memories.

A number of concepts for the data souvenir were created (Fig. 7) in order to explore the design space and to look at issues such as ease of production, cost and customisation. These concepts included generative postcards, an overlay for a street map, and a set of travel or identification papers. Each of these connected in some way to the exhibition, whether through the use of place (the street map), the type of object (the travel papers), or the content used to create them (the postcard).

The postcard concept was selected based on considerations such as the number of expected visitors (about 20,000), production process and cost. Industrial printers and paper used to print tickets for events were considered; such a technology is very fast and reliably prints thousands of cards before any maintenance for ink or paper is needed. In addition, the card background can be pre-printed on both sides with a highquality customised image in colour (Fig. 8), while patterns in black can be generated and printed dynamically so as to implement the personalisation component (Fig. 9).

The background graphics use the visual metaphor of crossing lines representing the Atlantic Wall (in orange) and the lives of the people around it (in blue), as they connect with or intersect with the wall. The design draws some aesthetic influences from aerial images from the archive of the city to give cohesion as the exhibition features much content based around maps and aerial photographs. The colours, orange and blue, also feature prominently in the exhibition design (Fig. 1). 


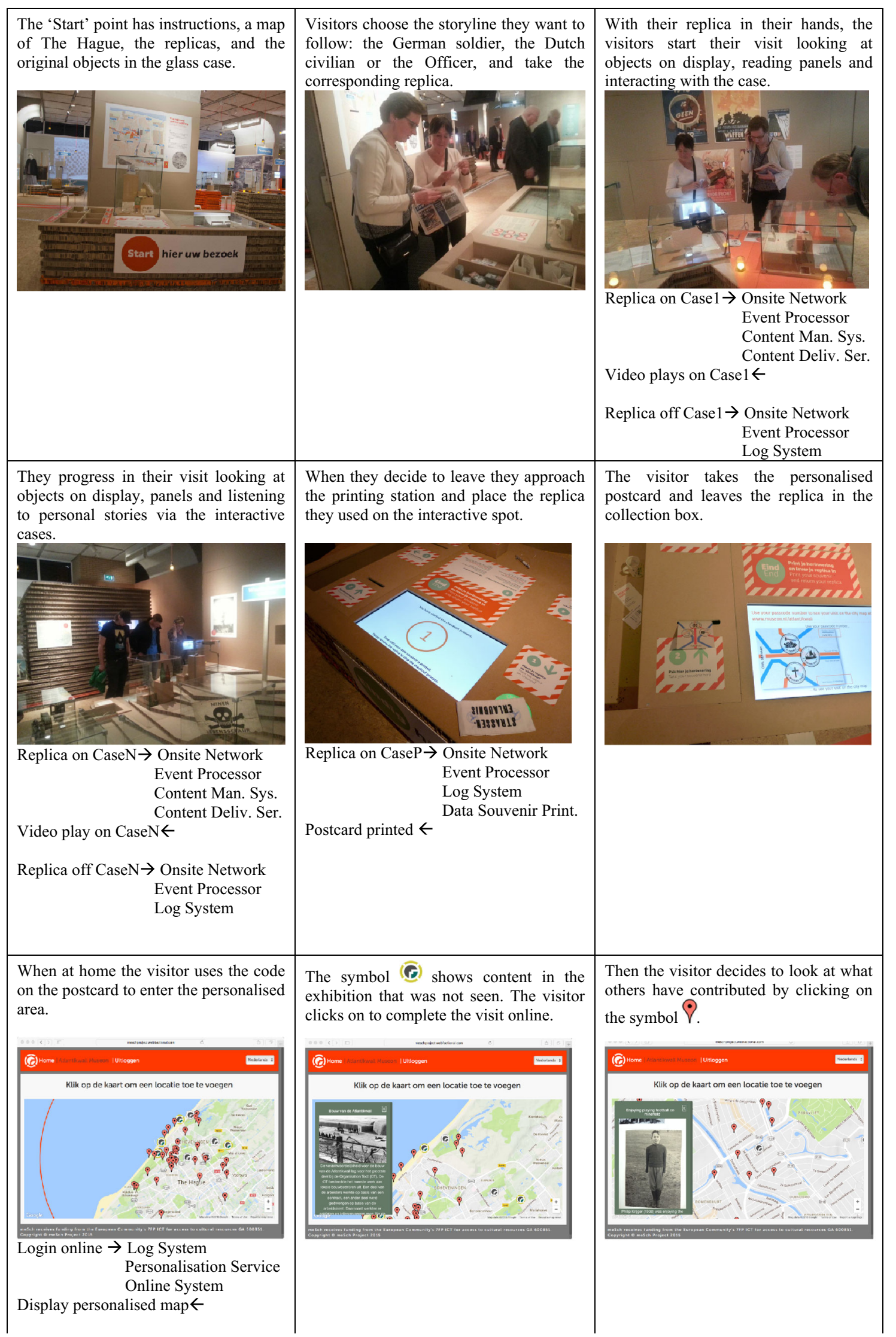


4Fig. 6 A storyboard of a visitor interacting in the exhibition and later online and how their action triggered some components in the architecture. The storyboard follows the visitor; some steps do not trigger any action in the system
When the visit (described in the previous section) is concluded, the visitor approaches the souvenir point to print their personalised card. As the augmented replica is placed on the last interactive spot, the data log recorded

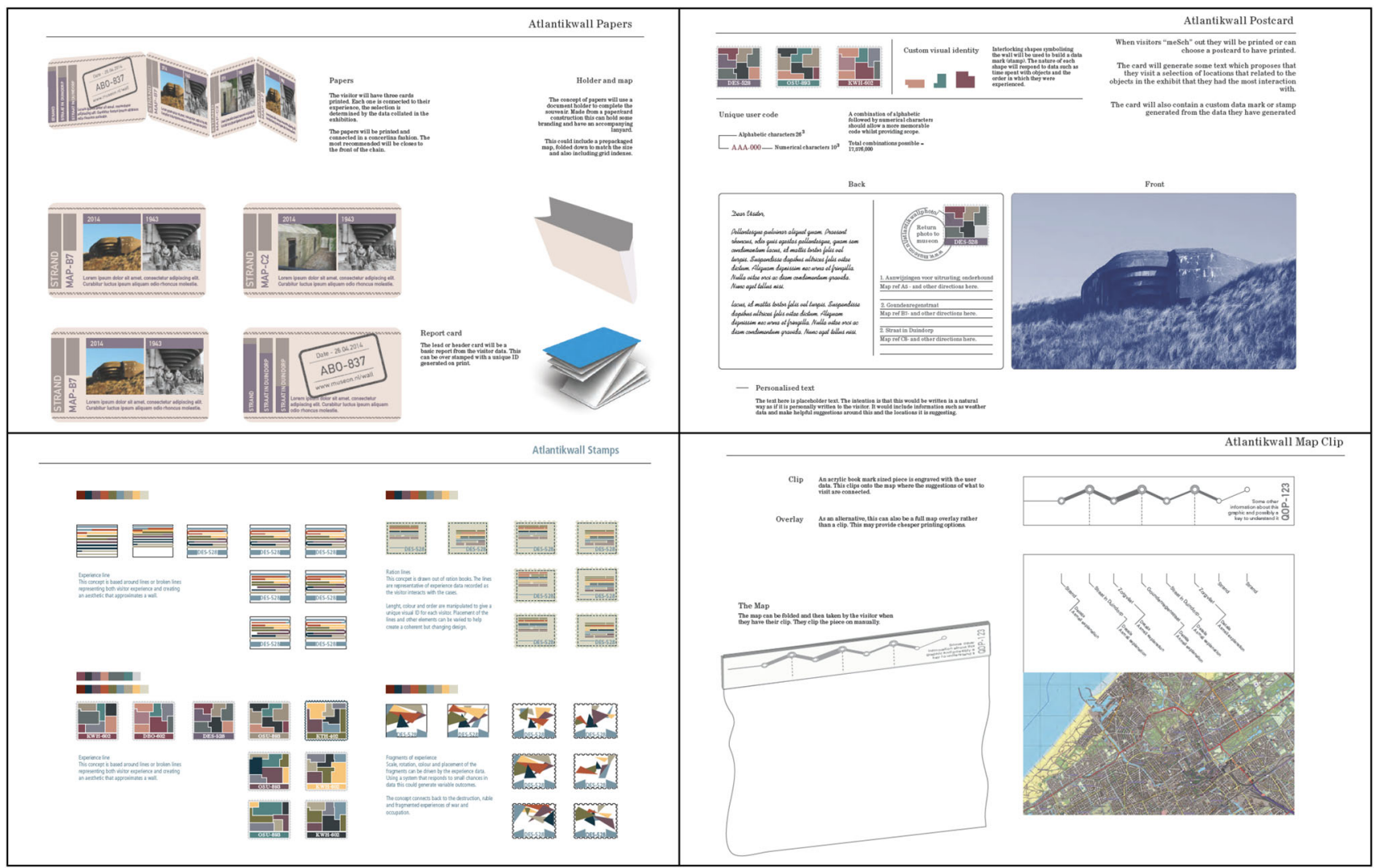

Fig. 7 Different concepts explore at the creative phase: a set of foldable tickets (top left); a written postcard with a personalised stamp (top right); different personalised stamps (bottom left); and a layered and annotated city map (bottom right)

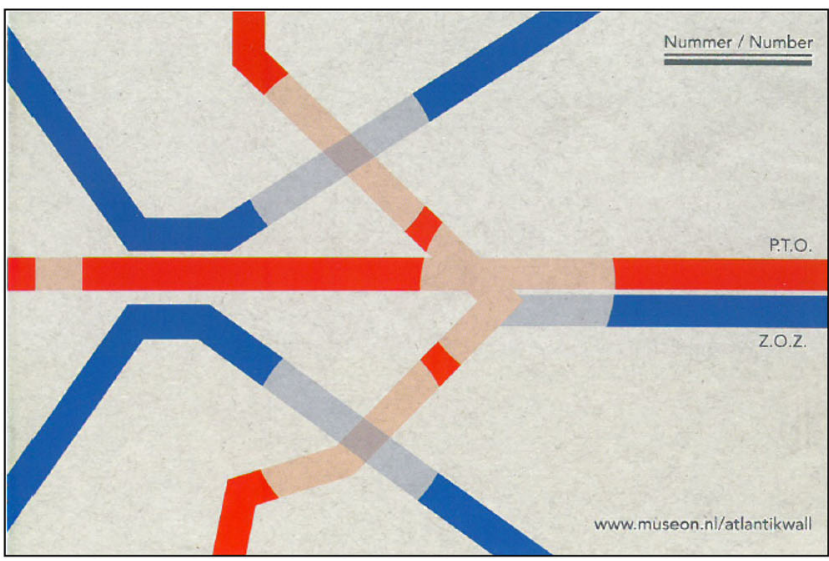

Fig. 8 The standard pre-printed postcard front and back. The front has predisposed areas for the printing that is done dynamically after the analysis of the logs (Fig. 9); the back shows a stylised map of The

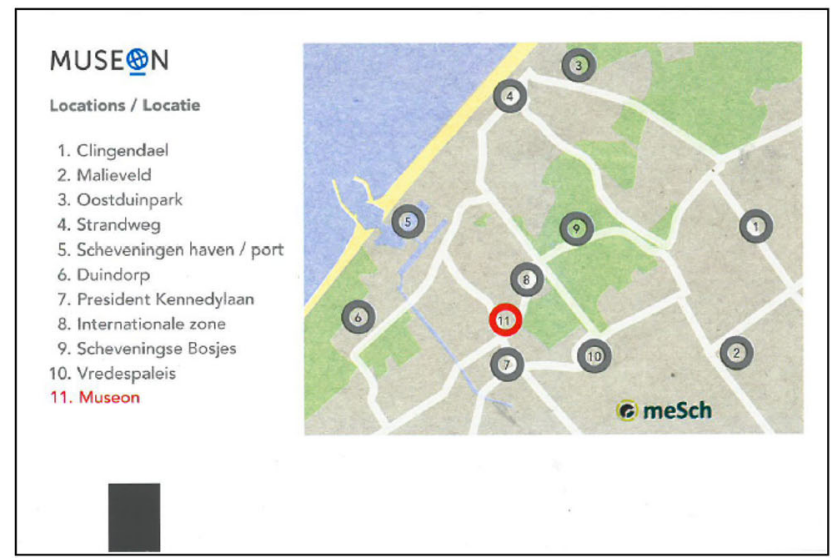

Hague with the locations represented in the exhibition indicated. The numbers on this map also match the ones on the stamps 
during the visit is processed to create the personalised print for the front of the card (Fig. 9). Aspects of the visit are extracted, such as the preferred language and the perspective (the personal story) that the visitor chose. The log data (the order of the interactive cases visited together with the start and stop time of content playback) are processed to determine the three interactive cases with which the visitor interacted for the longest period of time. These are then printed as "stamps" similar to those on travel documents during WWII. As each display case represents a specific location in The Hague, each case is represented by a unique stamp as though the visitor had been granted access to that location. The text on the stamp gives the name of the location within the city, while the image represents the object on display in the corresponding case. Figure 10 shows the ten stamps created for the exhibition.

The personalised postcard is a materialisation of the visit experience captured in the data log. A 6-digit personal access code printed on the top right of the postcard (see Fig. 9) gives access to the online post-visit experience website. This website is based on The Hague city map annotated with curated content from the exhibition and enriched by visitors' contribution (Fig. 11). In setting up the website, the curators aimed at collecting personal memories of The Hague in relation to the Atlantic Wall. Entering their personal code enabled the visitor to add content. At a glance, the online visitor can see which content corresponds to the curated Atlantic Wall exhibition (marked with and which content was contributed by visitors (marked with $\odot$ ). The content from the exhibition is further distinguished in what has been seen when at the exhibition (the logo is displayed in colour) versus content that has not been seen (the logo in grey) (Fig. 11). Similarly, the different colour in the marker for the visitorcontributed content distinguishes that of other visitors (in red) from that contributed by the visitor him/herself to the website (in green) (Fig. 11). The different markers, and their associated content, are designed to both show information at a glance and to stimulate the visitor to interact with the system and add their own stories or memories. By showing the visitor the information regarding the cases in the exhibition we remind them of what they have seen or offer the opportunity to look at what has been missed during the visit. By showing them other visitors' content, we aim to encourage them to submit content of their own.

Finally, it is important to notice that the card gives access to visit information held by the museum without the need to leave any personal data such as name or email

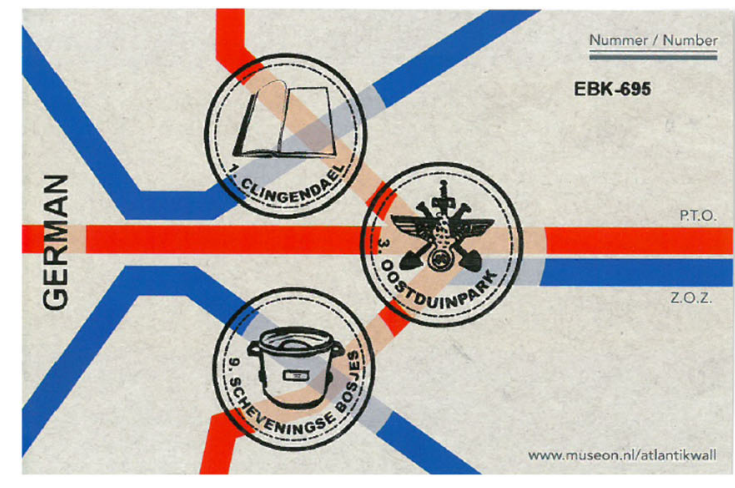

Fig. 9 The personalised souvenir summarises the highlights of the visit. The postcard on the left shows the visitor received the English narratives, followed the story of the German and spent the most time

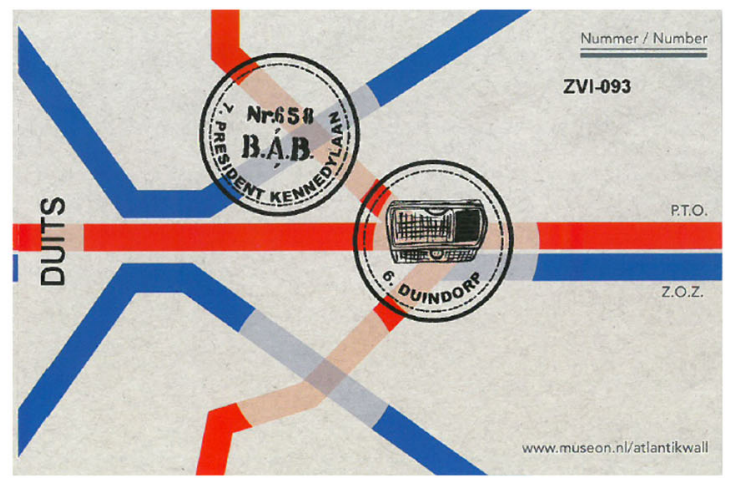

at locations 1, 3 and 9; the postcard on the right shows the language was Dutch, the perspective chosen was that of the German soldier and only two locations were visited, 6 and 7
Fig. 10 The ten different stamps one for each station in the exhibition. Each one represents an object on display and a location in the city (that fits the map on reverse, see Fig. 8)
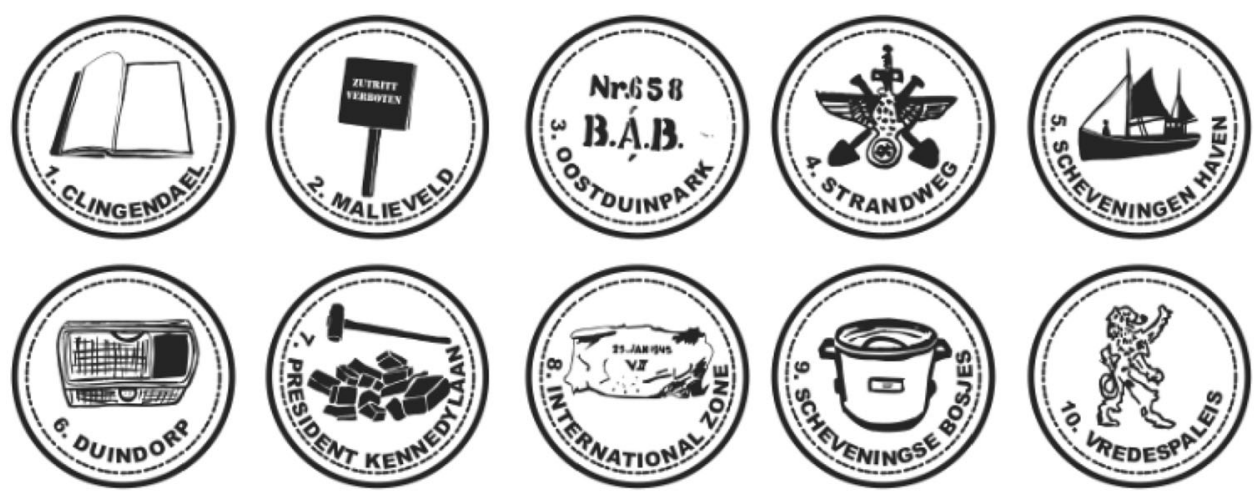


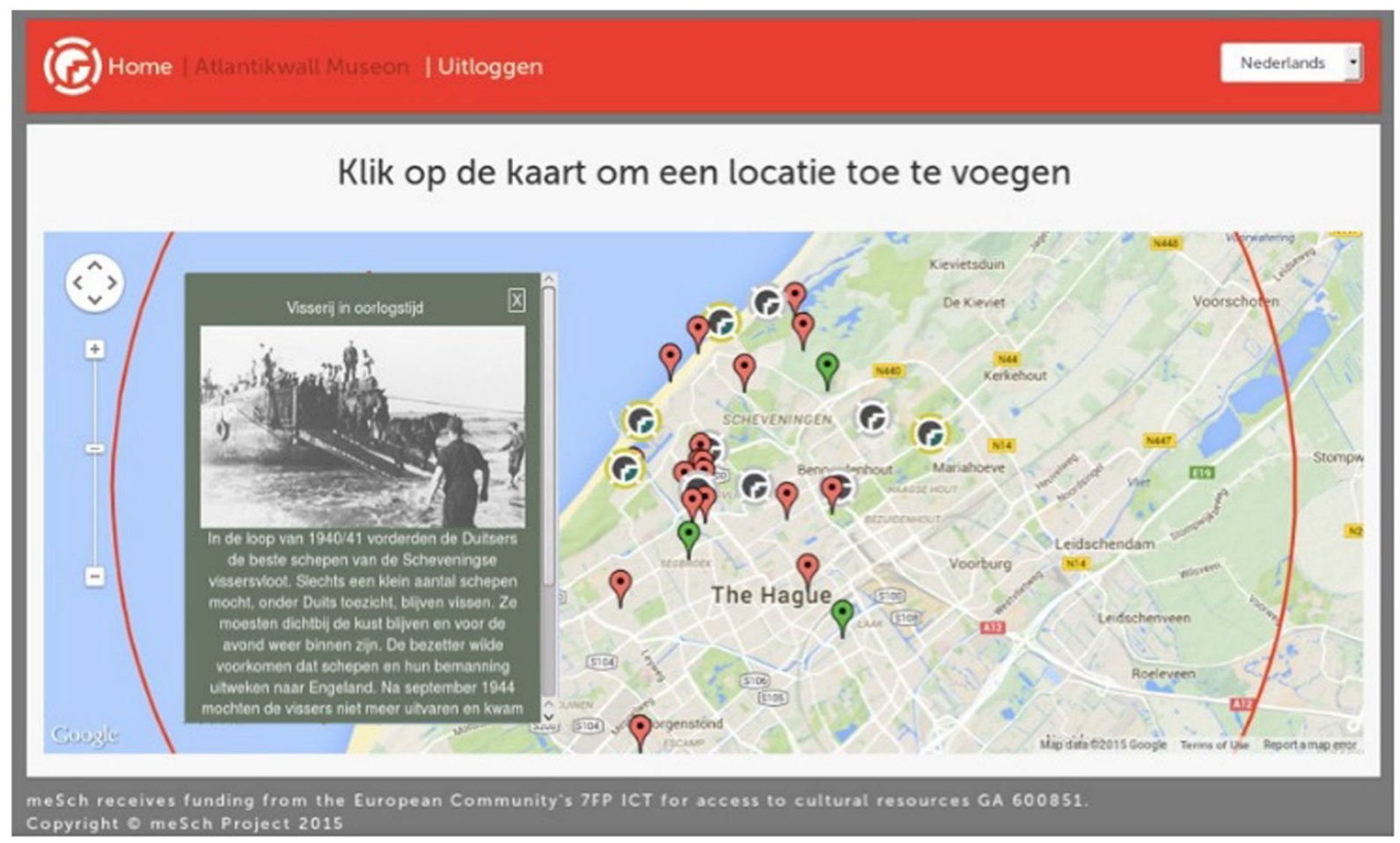

Fig. 11 The view of the Atlantic Wall online. The small window shows the specific content for a point

address. Visit logs are anonymous and linked only to the unique passcode on the postcard. If you have your postcard, then your visit and the extra content is accessible to you. Both curators and visitors who are becoming more aware of the concerns around properly managing sensitive personal data appreciated this design feature.

\section{Deployment within the exhibition}

The Atlantic Wall exhibition was opened to visitors from April to October 2015. During this time, we held a number of different evaluations to assess different aspects of the visitor experience [18]. Relevant to this paper are a set of naturalistic observations and the analysis of the logs recorded through the use of the replicas within the exhibition and the online access via the postcard.

The naturalistic observations enabled us to gain a good understanding of how the visitor experience evolved. The exhibition flow was open plan, meaning that there was no prescribed flow through the exhibition: visitors entered at any point, moved freely and left at any point. The lack of signage for the start (where the replicas are picked up) and the souvenir printing station meant visitors did not know there was an interactive activity on offer in addition to the traditional exhibition of objects and panels. As a result, the interactive cases were used only by a minority of visitors who entered the exhibition from where the replicas were displayed. We observed visitors without replicas approaching visitors with the replicas asking where they could collect their replica too, so as to have the same enriched experience. A few weeks after the opening the museum introduced signage to clearly indicate there was a start and an end point (Fig. 6 shows the start point where the replicas are picked up, and Fig. 12 shows the end point where the postcard is printed and the replicas returned); it also added further information on how to use the replicas and additional information about the souvenir was also placed at the start point as to invite visitors to complete the experience with the printing and collecting of their personalised postcard. The signage substantially increased the number of visitors using the replicas during the visit and we recorded an increase in printing the souvenirs at the end, although we observed that many continued to overlook it as they returned their replicas at the start, where they had picked it up. Indeed, this is an understandable behaviour and in hindsight we should have designed the start and stop as part of the same interactive station, so as to make sure visitors would not miss it unintentionally. Indeed, some visitors did not show any particular interest in the souvenir: we observed a few visitors looking at the souvenir station but not going through the process of actually printing. Conversely, we observed pairs and small groups of people visiting together selecting different replicas, going through the exhibition and then printing postcards: as the postcards were different (as the 

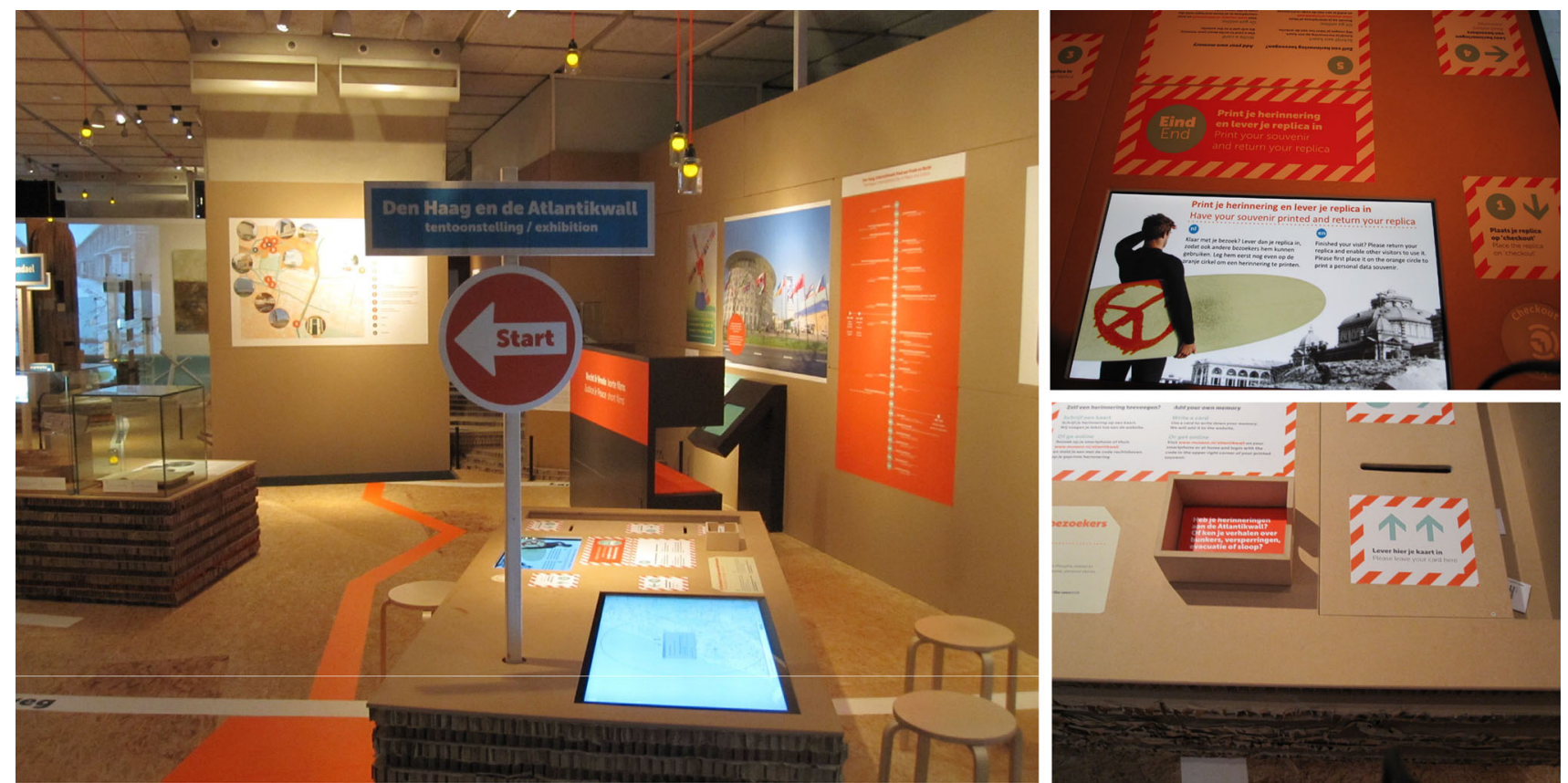

Fig. 12 The printing station after a sign was added to direct the visitors towards the start point to collect the replicas. The print station has a large touch screen to explore the map of The Hague with the visitors' contribution (bottom right in the left image); a smaller screen

experiences were different), this provoked discussions in the group on what was most liked and the invitation from a partner to listen to another story they particularly liked.

These observations derive from a naturalistic approach and visitors were therefore observed but not approached. For a period of time, museum staff were present on the exhibition floor to offer explanations and support: when visitors were shown the printing station and it was explained how the postcard could be used, the feedback collected was very positive. Visitors appreciated the gift of a souvenir as a memento of their visit. The fact that the card was personalised was not always automatically understood, but visitors in a group who followed different paths were observed comparing cards, indicating that a personalised souvenir can be a good way to invite visitors to reflect on their visit, an important step in the trajectory of experience [3]. This observation brings the question of whether the personalisation mechanisms of the system should be explained or made more evident. For example, should we include some explanation on the card itself or, better yet, at the printing point. Also, should the stamps on the card be shown at the cases that they correspond to, so as to make the connection more obvious? What we can state is that the card was appreciated for the very high quality of the print and the interesting design. There have been no reports from museum staff of cards being left behind in the museum, indicating a high interest by the visitors in taking the souvenirs away with them.

Another source of feedback was the analysis of the logs automatically recorded by the system during the visit and for the instruction video next to a slit where the postcard comes out (right column, top), and a box for hand-written suggestions (right column, bottom)

then the online access and use. In the 7 months, the exhibition was open a total of 14,853 visitors used the replicas in the interactive parts of the Atlantic Wall exhibition. Of these visitors, $1557(\sim 10 \%)$ printed their data souvenir. The fact that not every visitor that used the replicas printed the souvenir can be explained by the observations: many returned the replica at the start so overlooked the printing station, many did not go through all the exhibition so missed to walk by the printer, and many noted the printing but decided not to use it. This last behaviour is somewhat surprising given the positive feedback collected by the museum staff when the postcard was specifically discussed; we can therefore only speculate that possibly this is due to the very unfamiliar situation of print-your-own-souvenir that could be completely removed if a different dynamic was implemented, e.g. a member of staff collecting the replica, printing the postcard and handing it out to the visitors.

As the souvenir was also intended to enable access to the online system for gathering personal contributions, we also monitored the use of the passcodes. It should be noted that, while the needed information to access the content online was printed on the postcard, the instructions on how to proceed were not. This information was given in the form of an animation (Fig. 4) displayed at the printing station. We believe this had a negative impact on the use of the online system as many visitors may not have paid attention to the video or may have forgotten what the code on the 
postcard was for. Indeed, although the information on how to go online was on the postcard (see Figs. 4, 9), it was in a small print and not fully explained and therefore difficult to decode or remember.

Of the 1557 visitors who printed the card, only 39 ( $\sim 2.5 \%$ ) logged into the online post-visit exhibition, contributing overall 62 content points to the map (Fig. 4, last frame). The majority of the user content points added were created towards the centre of The Hague and were textual with only a few supported by old photographs. The location of the user content points does not particularly map to the locations in the exhibition. However, one area, the Statenkwartier, which was almost completely demolished in order to build additional Atlantic Wall defences, showed a high concentration of visitor contributions. As the visitor contribution was minimal with respect to the curators' expectations, time was spent in understanding why people were not willing to contribute. Staff from Museon have reported that visitors were very happy to share stories and memories with them on the exhibition floor, but were reluctant to go online, even if museum staff offered to help. The reason why willingness to share stories did not translate into active contribution could be explained in many ways: (1) the visitors who had personal and family memories to share were elderly or ageing and may not feel familiar enough with technology to go online and contribute; (2) poignant memories need a listening human being; (3) instructions on how to get online were given in the video when the card was printed (Fig. 4), key information was on the card but perhaps was not clear enough so people did not know/remember how to do it; and (4) when a visitor has left the exhibition, the interest has passed and the effort to contribute when at home is too high. The last two points can be addressed: a new card with a new background and clearer instructions could be designed. To enable visitors to add content while at the exhibition itself (the option to contribute content at the interactive tabletop was discarded at design time by the curators as they wanted to check each visitor contribution before it was displayed at the exhibition), the museum added cards and a box for people to write and leave their contributions in paper form (Fig. 12 bottom right); the museum personnel would then upload the contents of the cards on the system on behalf of the visitors.

\section{Guidelines and conclusion}

The research reported in this paper is the first example of the automatic generation of a personalised tangible data souvenir that acts as a memento of a museum visit and bridges the gap between the physical and the online experience. Our work showed that the uptake of the souvenir was affected by factors outside our control, i.e. the exhibition layout and signage on the exhibit floor. However, even for those visitors who did print the card, its meaning and the relationship with their personal visit was not clear. More research is needed to understand whether this information is actually desired by the visitor or whether, instead, the gift of a beautiful object as a memento of the visit is enough and the additional explanation on how the card was made could be available online. The crucial point is to find ways to increase the number of visitors accessing the online experience. A clear guideline is to make sure the information on the souvenir is not only present, but that it is completely obvious how to use it. This can be a challenge, as blunt instructions can clash with aesthetics: designers may need to choose one or the other. A souvenir that has clear instructions on how to get online is essential. We also need to determine if the underuse of the website is due to lack of know-how or lack of interest. Museums are devoting much effort to provide post-visit experiences that, in the second case, may not be worth pursuing. An alternative approach is to provide tools that enable the museum to offer a post-visit experience at a limited cost: as the digital content for the exhibition has been created and the log of the visit collected, the two can be used to automatically create online personalised pages (Fig. 13). These pages could include views of what has been missed in the exhibition as well as content from public online resources recommended on the bases of the visit; the museum can also use these pages to publish newsletters or advertise new exhibitions.

A positive finding from this deployment is that visitors who generate their own data souvenir take time to look at them and keep them. They do not seem to leave them behind or dump them at the museum. This is inline with our expectations based on the research into souvenirs and memories. The feedback collected on the exhibition floor also shows that the postcards are seen as being something worth keeping. A second guideline then is that high quality printing and beautiful design can add value and encourage visitors to keep the gift.

A further guideline is to design for reliability. Discussions with curators and technical staff from Museon highlighted the importance of a reliable, low maintenance system. Previous experiences with printers and other such systems on the museum floor had been quite negative, so that they were seen as more trouble than they were worth. Much work was put into producing a system that was reliable enough for deployment in the wild. This included the use of commercial grade thermal printers, capable of producing 5000 postcards before needing to be loaded with more card stock and that did not need to be loaded with any other media such as ink or toner. Reliability is also a key issue for visitors, an unreliable system, will provide a poor 


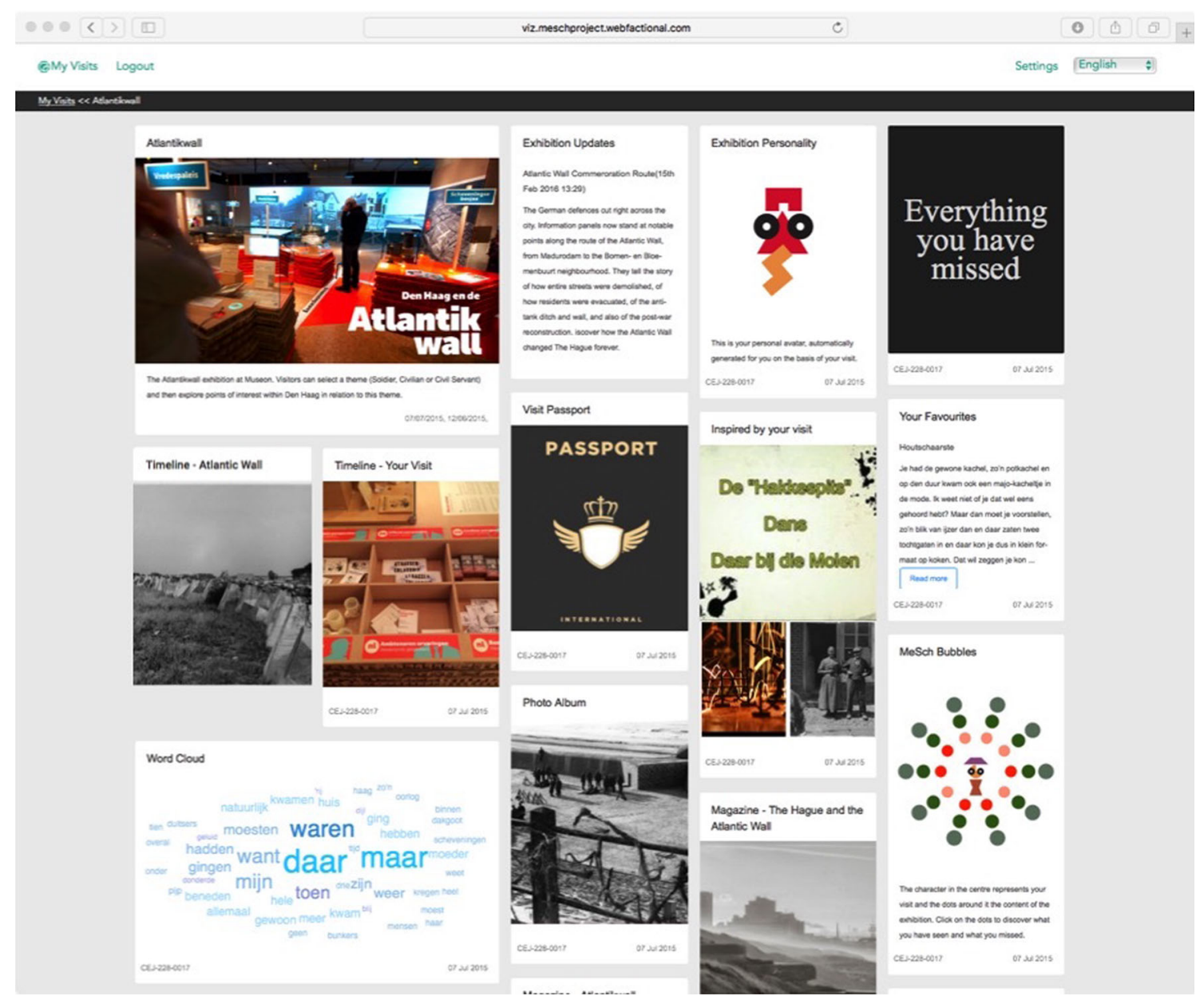

Fig. 13 The automatically generated personalised pages that use the exhibition content, museum material and recommend external resources on the bases of the recorded $\log$

experience for the visitor and can lead to frustration. Finally, the printing was almost instantaneous, so there was no delay between depositing the replicas and collecting the postcard.

To conclude, our exploration of the automatic generation of a tangible personalised souvenir created on the basis of logged data was very positive and opened a range of possible further research actions. Curators were keen for visitors to take away a memento of the exhibition. Visitors were fond of the cards and took them home with them. The logging of the visit enabled dynamic content creation and many more visualisations could be designed for both the souvenir and the online experience. The key issue is how to increase the number of people that go online, although this point needs much more field research as it is not at all clear if the under use is due to lack of information on how-to or lack of interest by visitors.

Acknowledgements The research described in this paper was conducted as part of the meSch project, Material Encounters with Digital Cultural Heritage. meSch (2013-2017) receives funding from the
European Community's Seventh Framework Programme, "ICT for access to cultural resources" (ICT Call 9: FP7-ICT-2011-9) under the Grant Agreement 600851.

Open Access This article is distributed under the terms of the Creative Commons Attribution 4.0 International License (http://crea tivecommons.org/licenses/by/4.0/), which permits unrestricted use, distribution, and reproduction in any medium, provided you give appropriate credit to the original author(s) and the source, provide a link to the Creative Commons license, and indicate if changes were made.

\section{References}

1. Aipperspach R, Hooker B, Woodruff A (2011) Data Souvenirs: environmental psychology and reflective design. IJHCS 69(5):338-349

2. Anderson L, Littrell MA (1995) Souvenir-purchase behavior of women tourists. Ann Tour Res 22(2):328-348

3. Benford S, Giannachi G, Koleva B, Rodden T (2009) From interaction to trajectories: designing coherent journeys through user experiences. In: Proceedings of the SIGCHI conference on human factors in computing systems (CHI '09). ACM, New York, pp 709-718 
4. Chianese A, Picccialli F (2015) Improving user experience of cultural environment through IoT: the 'Beauty or the Truth' case study. Smart Innov Syst Technol 40:11-20

5. Chianese A, Piccialli F, Valente I (2015) Smart environments and cultural heritage: a novel approach to create intelligent cultural spaces. J Locat Based Serv 9(3):209-234

6. Ciolfi L (2013) The collaborative work of heritage: open challenges for CSCW. In: Proceedings of European conference on computer supported cooperative work-ECSCW 2013. Springer, London, pp 83-101

7. Ciolfi L, Bannon LJ, Fernström M (2008) Including visitor contributions in cultural heritage installations: designing for participation. Mus Manag Curatorship 23(4):353-365

8. Davidson B, Lee Heald C, Hein G (1991) Increased exhibit accessibility through multisensory interaction. Curator 34(4):273-290

9. Falk JH (2009) Identity and the museum visitor experience. Left coast Press, Walnut Creek

10. Falk JH, Dierking LD (2013) Museum experience revisited. Left Coast Press, Walnut Creek

11. Giaccardi E (2012) (ed) Heritage and social media: understanding heritage in a participatory culture. Routledge, London

12. Gordon B (1986) The souvenir: messenger of the extraordinary. J Popul Cult 20(3):135-146

13. Hashimoto A, Telfer DJ (2007) Geographical representations embedded within souvenirs in Niagara: the case of geographically displaced authenticity. Tour Geogr 9(2):191-217

14. Heath C, vom Lehn D, Osborne J (2005) Interaction and interactives: collaboration and participation with computer-based exhibits. Public Underst Sci 14:91-101

15. Hornecker E (2008) "I don't understand it either but it's cool"visitor interactions with a multi-touch table in a museum. In: Proceedings of IEEE Tabletop, pp 121-128

16. Kidd J (2013) Museums in the New Mediascape. Ashgate, Farnham

17. Lee M-H, Cha S, Nam T-J (2015) Patina engraver: visualizing activity logs as patina in fashionable trackers. In: Proceedings of the 33rd annual ACM conference on human factors in computing systems (CHI '15). ACM, New York, pp 1173-1182

18. Marshall MT, Dulake N, Ciolfi L, Duranti D, Kockelkorn H, Petrelli D (2016) Using tangible smart replicas as controls for an interactive museum exhibition. In: Proceedings of ACM tangible, embedded and embodied interactions TEI16. ACM Press, New York, pp 159-167

19. McIntyre C (2010) Designing museum and gallery shops as integral, co-creative retail spaces within the overall visitor experience. Mus Manag Curatorship 25(2):181-198

20. Murawski M (2014) Student learning in museums: what do we know? Art museum teaching. https://artmuseumteaching.com/ 2014/11/19/student-learning-in-museums-what-do-we-know/. Accessed 20 July 2016
21. Nigel M, Pritchard A (2005) On souvenirs and metonymy: narratives of memory, metaphor and materiality. Tour Stud 5(1):29-53

22. Nissen B, Bowers J (2015) Data-things: digital fabrication situated within participatory data translation activities. In: Proceedings of the 33rd annual ACM conference on human factors in computing systems (CHI '15). ACM, New York, pp 2467-2476

23. Nissen B, Bowers J, Wright P, Hook J, Newell C (2014) Volvelles, domes and wristbands: embedding digital fabrication within a visitor's trajectory of engagement. In: Proceedings of the 2014 conference on designing interactive systems (DIS '14). ACM, New York, pp 825-834

24. Packer J, Bond N (2010) Museums as restorative environments. Curators 53(4):421-436

25. Petrelli D, De Angeli A, Convertino G (1999) A user-centered approach to user modelling. In: Proceedings of the 7 th international conference on user modeling UM'99, pp 255-264

26. Petrelli D, Ciolfi L, van Dijk D, Hornecker E, Not E, Schmidt A (2013) Integrating material and digital: a new way for cultural heritage. ACM Interact 20(4):58-63

27. Petrelli D, Dulake N, Marshall MT, Pisetti A, Not E (2016) Voices from the war: design as a means of understanding the experience of visiting heritage. In: Proceedings of the 34th annual ACM conference on human factors in computing systems (CHI '16). ACM, New York, pp 1033-1044

28. Serrell B, Raphling B (1992) Computers on the exhibit floor. Curator Mus J 35:181-189

29. Simon N (2010) The participatory museum. Santa Cruz, Museum 2.0

30. Stock O, Zancanaro M, Busetta P, Callaway C, Krüger A, Kruppa M, Kuflik T, Not E, Rocchi C (2007) Adaptive, intelligent presentation of information for the museum visitor in PEACH. UMUAI 17(3):257-304

31. Szymanski M et al (2007) Sotto Voce: facilitating social learning in a historic house. Int J Comput Support Coop Work CSCW 17:5-34

32. Taylor B (2010) Reconsidering digital surrogates. In: Dudley S (ed) Museum materialities. Routledge, London, pp 175-184

33. Vavoula G, Sharples M, Rudman P, Meek J, Lonsdale P (2009) Myartspace: design and evaluation of support for learning with multimedia phones between classrooms and museums. Comput Educ 53(2):286-299

34. vom Lehn D, Heath C (2003) Displacing the object: mobile technology and interpretive resources. In: Proceedings of museum and the web-MW03. http://www.archimuse.com/pub lishing/ichim03/088C.pdf. Accessed 20 July 2016

35. Wehner K, Sear M (2010) Engaging the material world. In: Dudley S (ed) Museum materialities. Routledge, London, pp 143-161 